The absence of contrast enhancement and hypodensity on computed tomographic scanning usually suggests the diagnosis of cystic lesions. Opacification of the thoracic collateral veins can be very difficult to obtain, and it depends on the amount of contrast material, the injection rate, and the timing of the administration. ${ }^{4}$

In the present case the site and density of the mass were consistent with the diagnosis of a pleuropericardial cyst.

The possibility of a mediastinal varix was not considered for the absence of other varicose abnormalities and the absence of clinically evident portal hypertension. The possibility of a membranous obstruction of the inferior vena cava was considered after surgical exploration and confirmed by means of echocardiographic Doppler examination.

The site of this rare abnormality was atypical. Of the 4 cases of paracardiac mass caused by mediastinal varices reported by Chung and colleagues, ${ }^{3}$ all were on the left side, and the pattern of drainage was from the hepatic veins through the left inferior phrenic vein to the left pericardiophrenic vein.

In the presented case, on the basis of surgical exploration, it was reasonable to assume that the drainage was from the right inferior phrenic vein through the right pericardiophrenic vein into the right thoracic vein. ${ }^{5}$
This observation suggests that isolated varicose abnormality of the pericardiophrenic vein should be considered in the differential diagnosis of mediastinal plurilobate masses. In this case a different timing in image uptake after contrast injection could support such a diagnosis and justify magnetic resonance, venocavography, or both, to avoid invasive diagnostic procedures such as videoassisted thoracoscopy.

\section{References}

1. Millward SF, Ramsewak W, Joseph G, Jones B, Zylak CJ. Pericardial varices demonstrated by computed tomography. J Comput Assist Tomogr. 1985;9:1106-7.

2. Podbielski FJ, Sam AD, Halldorson AO, Iasha-Sznajder J, Vigneswaran WT. Giant azygos vein varix. Ann Thorac Surg. 1997;63:1167-9.

3. Chung JW, Im JG, Park JH, Han JK, Choi CG, Han MC. Left paracardiac mass caused by dilated pericardiacophrenic vein: report of four cases. AJR Am J Roentgenol. 1993;160:25-8.

4. Trigaux JP, vanBeers B. Thoracic collateral venous channels: normal and pathologic CT findings. J Comput Assist Tomogr. 1990;14:769-73.

5. Lawler LP, Fishman EK. Pericardial varices: depiction on three-dimensional computed tomographic angiography. AJR Am J Roentgenol. 2001;177:202-4.

\title{
Foreign-body excretion through the bronchial stump after extrapleural pneumonectomy
}

\author{
Kenichi Okubo, MD, and Yasunori Kurahashi, MD, Gifu, Japan
}

$\mathrm{F}$ oreign-body excretion is a bioresponse of the human body. Bronchial foreign bodies commonly occur through aspiration or inhalation. We present a rare case of the excretion of a foreign body through the bronchial stump 19 months after pneumonectomy.

\section{Clinical Summary}

A 52-year-old man had a high fever and chest discomfort. He underwent a left extrapleural pneumonectomy for malignant pleural mesothelioma 19 months earlier. He received postoperative chemotherapy, which consisted of 4 cycles of cisplatin, doxorubicin, and cyclophosphamide, and sequential radiation therapy for

From General Thoracic Surgery, Gifu National Hospital, Gifu, Japan

Received for publication April 11, 2004; revisions received May 7, 2004; accepted for publication May 24, 2004.

Address for reprints: Kenichi Okubo, MD, General Thoracic Surgery, Gifu National Hospital, 5-1-1 Hinohigashi, Gifu 500-8718, Japan (E-mail: okubo@gifu.hosp.go.jp).

J Thorac Cardiovasc Surg 2005;129:449-50

$0022-5223 / \$ 30.00$

Copyright $\odot 2005$ by The American Association for Thoracic Surgery

doi:10.1016/j.jtcvs.2004.05.028 the entire hemithorax of $56 \mathrm{~Gy}$ in total. ${ }^{1,2}$ Blood count showed luekocytosis, and chemistry showed an increased C-reactive protein level. Chest radiography showed no abnormal lesions except for left-side opacity after pneumonectomy. Computed tomography of the chest and the abdomen showed no evidence of recurrence of malignant pleural mesothelioma. Culture of thoracentesis fluid showed no growth of microorganisms. Bronchoscopic examination revealed a foreign body, a whitish cottony material, at the left main bronchial stump (Figure 1). Endoscopic extraction with forceps identified a hemostat of oxidized cellulose (Figure 2). After the extraction, a blue suture was translucently identified in the mucosa of the bronchial stump. Bronchopleural fistula was not seen during or after the extraction. Culture of the material revealed Haemophilus species. After the removal of the infected foreign body, the patient recovered quickly and has been doing well for 3 years.

The bronchial stump at the left extrapleural pneumonectomy was hand sutured with interrupted polypropylene sutures (3-0 Prolene; Ethicon Inc, Somerville, NJ) and reinforced with a pedicled intercostal muscle by using the same polypropylene sutures for bronchus. On the next day, the patient underwent a re-exploration of the thorax as a result of the excessive blood loss. After hemostasis was obtained, cotton-type oxidized cellulose (Oxycel; Sankyo Co, Tokyo, Japan) was inserted into the mediastinum as a hemostat. Bronchoscopic examination 4 weeks after the pneumo- 


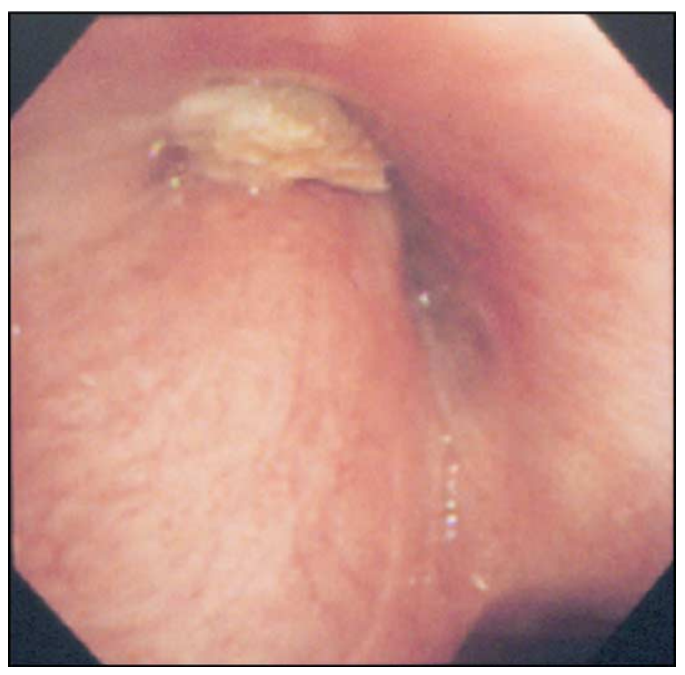

Figure 1. Bronchoscopic finding of the left main bronchus. A whitish cottony material was identified at the bronchial stump.

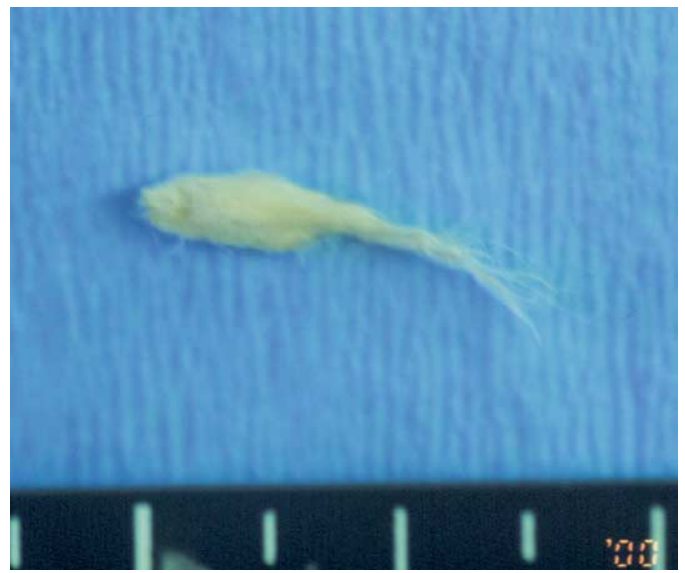

Figure 2. Oxidized cellulose extracted with forceps bronchoscopically.

nectomy showed normal findings at the bronchial closure. For 19 months of postoperative follow-up, the patient had been without any symptoms of bronchopleural fistula, and chest radiography had never shown an air-fluid level in the left thorax. The bronchial stump should have been airtight since the extrapleural pneumonectomy.

\section{Discussion}

In the literature most foreign bodies found in the airway are the result of aspiration or inhalation. On the other hand, several bronchial foreign bodies that were not inhaled have been reported. Migration of shrapnel from the pulmonary parenchyma into a bronchus 64 years after the injury was reported. ${ }^{3}$ Two foreign bodies with uncommon ways of entry were removed with a bronchoscope: one was a bullet that eroded in the right lower bronchus after having penetrated through a wound in the chest wall, and the other was a fragment of circular saw lodged in the right main bronchus after penetration through a wound in the neck. ${ }^{4}$ Recent literature also described expectoration of titanium staples in 3 patients many months after volume-reduction surgery for pulmonary emphysema. ${ }^{5}$ Jackson and Jackson ${ }^{6}$ mentioned that foreign bodies, especially metallic ones that cause little specific reaction, can reach the bronchi through penetration of the chest wall. However, few nonmetallic foreign bodies migrating into the airway have been reported.

Our patient appeared to have excreted a hemostat of oxidized cellulose from the thoracic cavity into the endobronchial lumen through the sutures of the bronchial stump. The foreign-body reaction of cellulose has been known to be mild in in vivo experiments. ${ }^{7}$ Although the mechanisms of the migration remain unknown, we would provide evidence of a rare nonmetallic foreign body in the airway through the bronchial stump.

\section{References}

1. Sugarbaker DJ, Strauss GM, Lynch TJ, Richard W, Mentzer SJ, Lee $\mathrm{TH}$, et al. Node status has prognostic significance in the multimodality therapy of diffuse malignant mesothelioma. J Clin Oncol. 1993;11: $1172-8$.

2. Sugarbaker DJ, Grarcia JP, Richards WG, Harpole DH Jr, HealyBaldini E, DeCamp MM Jr, et al. Extrapleural pneumonectomy in the multimodality therapy of malignant pleural mesothelioma. Result in 120 consecutive patients. Ann Surg. 1996;224:288-94.

3. Bogedain W. Migration of shrapnel from lung to bronchus. JAMA. 1984;251:1862-3

4. Aprigliano F. Bronchial foreign bodies: an uncommon way to entry. Ann Otol Rhinol Laryngol. 1990;99:695-7.

5. Oey I, Waller DA. Metalloptysis: a late complication of lung volume reduction surgery. Ann Thorac Surg. 2001;71:1694-5.

6. Jackson C, Jackson CL. Bronchoesophagology. Philadelphia (PA): WB Saunders; 1950. p. 13.

7. Miyamoto T, Takahashi S, Ito H, Inagaki H, Noishiki Y. Tissue biocompatibility of cellulose and its derivatives. J Biomed Mater Res. 1989;23:125-33. 